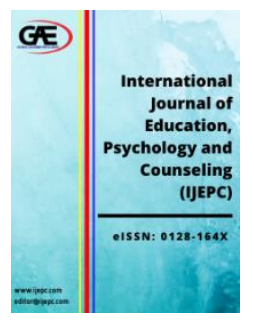

\author{
INTERNATIONAL JOURNAL OF \\ EDUCATION, PSYCHOLOGY \\ AND COUNSELLING \\ (IJEPC) \\ www.ijepc.com
}

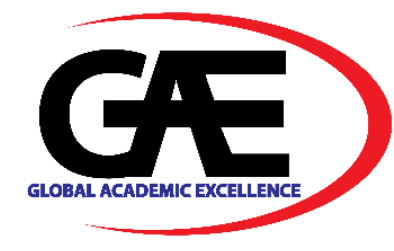

\title{
TRANSLATION PEDAGOGY VERSUS PEDAGOGICAL TRANSLATION IN LANGUAGE LEARNING
}

\author{
Nik Zaitun Nik Mohamed ${ }^{1}$, Ameiruel Azwan Ab Aziz ${ }^{2 *}$, Kamsilawati Kamlun ${ }^{3}$, Irma Wani Othman ${ }^{4}$ \\ 1 Faculty of Psychology and Education, Universiti Malaysia Sabah, Malaysia \\ Email: nzaitun@ums.edu.my \\ 2 Academy of Language Studies, Universiti Teknologi MARA Cawangan Melaka, Malaysia \\ Email: ameirul@uitm.edu.my \\ 3 Centre for the Promotion of Knowledge and Language Learning, Universiti Malaysia Sabah, Malaysia \\ Email:kamsi@ums.edu.my \\ 4 Centre for the Promotion of Knowledge and Language Learning, Universiti Malaysia Sabah, Malaysia \\ Email: irma@ums.edu.my \\ Corresponding Author
}

\section{Article Info:}

Article history:

Received date: 11.09 .2021

Revised date: 10.10 .2021

Accepted date: 15.11.2021

Published date: 30.11 .2021

\section{To cite this document:}

Nik Mohamed, N. Z., Aziz, A. A. A., Kamlun, K.. \& Othman, I. W. (2021). Translation Pedagogy Versus Pedagogical Translation In Language Learning. International Journal of Education, Psychology and Counseling, 6 (43), 83-96.

\section{DOI: $10.35631 /$ IJEPC.643008}

This work is licensed under $\mathrm{CC}$ BY 4.0

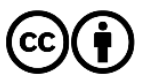

\begin{abstract}
:
This conceptual paper presents the review of literatures of a study related to Translation in Language Teaching (TILT) and Translation Training, It reviews related literature on translation theories and practices in bilingual/multilingual classrooms as well. The interplay of translation, multilingualism, multiculturalism and globalisation in today's ESL pedagogical reality demands translation to be employed in improving students' English language proficiency. Unfortunately, research indicates that teachers do not possess adequate knowledge on appropriate translation models to enable them to perform translation in language teaching (TILT). As a result, they ended up employing unplanned code switching and code-mixing techniques throughout their English language lessons. Studies have shown that translation educators also do not possess adequate competencies in training language teachers to translate due to discrepancy between the chosen modules and teachers' motivation. As a result, teachers failed to understand the purpose of such training. This conceptual paper, thus, attempts to conjure up two important concepts in translation studies: Pedagogical translation and translation pedagogy. Translation Pedagogy refers to the acquired knowledge on how to translate, whereas pedagogical translation refers to the actual process or practice of translation either in written or verbal form. The relevance of these two concepts in TILT are highlighted and discussed throughout this paper. A translation model is suggested as a guideline in providing training in TILT area. The result of this upcoming study may provide a direction in translation training for language teachers in Malaysia. It suggests that the concepts of
\end{abstract}




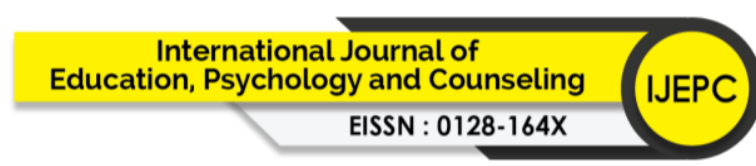

Volume 6 Issue 43 (November 2021) PP. 83-96

DOI 10.35631/IJEPC.643008

Special Issue: Issues and Challenges in English Education Pedagogical Translation (PT) and Translation Pedagogy (TP) should be incorporated into translation training modules. By doing so, both translation trainers and teacher trainees are able to understand the actual processes of translation itself in TILT.

Keywords:

Pedagogical Translation, Translation Pedagogy, Translation Studies, ELT

\section{Introduction}

Translation has long been regarded as one of the methods in ESL teaching, even though it has been belittled in various terms, such as "unhelpful to learning, unusable, dull, authoritarian, unpopular, artificial, and slows students down" (Cook, 2010: 125). However, the interplay of translation, bi/multiculturalism and globalisation in today's ESL pedagogical reality demands translation to be employed in improving students' English language proficiency. During the "multilingual turn" (Laviosa \& Gonzalez-Davies, 2020) of this 21st century, translation training among teachers/educators has suddenly gained its importance. Studies on this issue have been conducted either in translation studies, pedagogy or applied linguistics. Plethora of concepts connected to translation and language teaching (TILT) seem exhaustive.

Unfortunately, research indicates that teachers do not possess adequate knowledge on translation model to enable them to perform translation. As a result, they ended up employing unplanned code-switching techniques throughout their English language lessons (Noor Azaliya et al., 2019). Translation educators also do not possess adequate competencies in training language teachers to translate due to mismatch of the chosen module and teachers' motivation (Massey, 2020). As a result, teachers failed to understand the purpose of such training and lacked motivation to learn.

\section{Purpose Of Research And Research Questions}

This conceptual paper attempts to identify the concepts of translation pedagogy and pedagogical translation, and the relevance of these concepts in language teaching. Studies on descriptive translation studies in language teaching setting seem scarce. Thus, the following research questions will be posed:

1. What is translation pedagogy?

2. What is pedagogical translation?

3. How do both concepts merge in language teaching?

\section{Significance Of The Research}

This conceptual paper is significant as it provides a direction in constructing a module to teach translation to English language teachers in Malaysia. The study attempts to look into the connection that both translation pedagogy and pedagogical translation have upon a teacher in a process-oriented approach, instead of a product evaluation approach. In addition, it attempts to fill in the gaps of translation practice and training among English language teachers in Malaysia. In other words, this paper will enable educators and policymakers to know the trend and development throughout the years in the areas of translation in language teaching (TILT), translation training and education theories. 


\section{Limitation Of The Study}

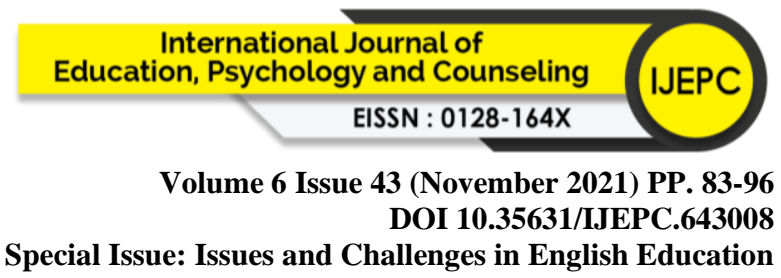

This conceptual paper is not extensive in terms of literature search on the theoretical aspects of translation. It only deals with descriptive and process-oriented theories. It does not study the end product or quality of a translator in a prescriptive manner. Instead, it looks into the process of translation itself from the beginning until the end. Thus, this study has limitation in investigation.

\section{Theoretical Overview}

\section{Translation and Theories}

Research in the area of Translation Studies has shown that there are two schools of thoughts in dealing with translation: Prescriptive and Descriptive methods. The Prescriptive group deals with the end products of translation, the translated texts, whereas the Descriptive group will study the processes of translation and factors affecting the translator and production of the translated texts. For the sake of this research, Descriptive theories and approaches will be employed.

An example of a descriptive theoretical framework is the idea of the Polysystem Hypothesis, which is based on the works of Russian formalists such as Tynjanov and Ejchenbaum. It was Even-Zohar who introduced this hypothesis in the 1980s (Toury, 2013). He considers all sorts of literary and semi-literary texts as an aggregate of systems. His task is to explore the relationship between translated texts and the literary polysystem following two directions: (i) how texts to be translated are chosen in the target culture and (ii) how translated texts adopt certain norms and functions as a result of their relation to other target language systems. These positions are analysed in terms of stratified codes such as primary-secondary, canonicalperipheral, high-low and innovatory-conservatory. He argues that this hypothesis enables one to observe the relationship between the positions of the translated texts and the other systems.

Toury (2013), a younger colleague of Even-Zohar, has introduced the concept of translational norms into the Polysystem Theory. These norms could explain the translation process at every level within the target literary system: preliminary and operational norms. The preliminary norms are connected to the translation policy and the directness of the translation activity. The operational norms may be related to the decisions made during the act of translation itself. As illustrated below: 


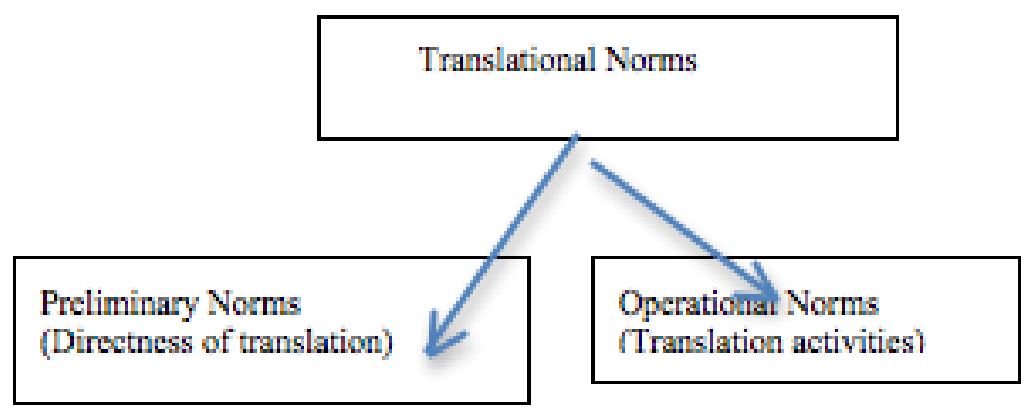

\section{Figure 1: Toury's Translational Norms (Adapted from Toury, 2013)}

Indeed, these norms may affect the matrix of the text in terms of what goes on between the source and target texts. He also introduced the concept of adequate translation in explaining the equivalence of the translated texts within the target literary system. Even though the Polysystem theory helps one to observe the connection between translated texts and the other systems within the target literary system, the whole hypothesis does not seem to work with other literary systems that do not share similar evolution. In looking for an alternative framework which may be used to describe the translation process in Malaysia, the one offered by Bassnett (2014) was chosen. Although both of these frameworks offer descriptive approaches in studying the position of translated texts within target culture, there is a sense of flexibility in these frameworks. A more general framework offered by Bassnett (2014), for instance, enables one to understand what is going on in the area of translation studies over the years. Her descriptive approach in dealing with various types of translations seems useful. Similar to Even-Zohar and Toury, she also believes in adopting an interdisciplinary approach in understanding what is going on in the translation activities.

In looking into specific aspects of information transfer from source to target texts, the descriptive framework suggested by Holmes (1988) also seems relevant. Through Holmes' work, one is able to see the processes involved in translation, which includes the mapping strategy in achieving equivalence in target text. A translator, according to him, has to deal with a hierarchy of correspondences, or the translator's poetics. His four forms of verse translations seem helpful in describing the translator's choice before translating poetry or other literary genres. As illustrated below: 
Volume 6 Issue 43 (November 2021) PP. 83-96

DOI 10.35631/IJEPC.643008

Special Issue: Issues and Challenges in English Education

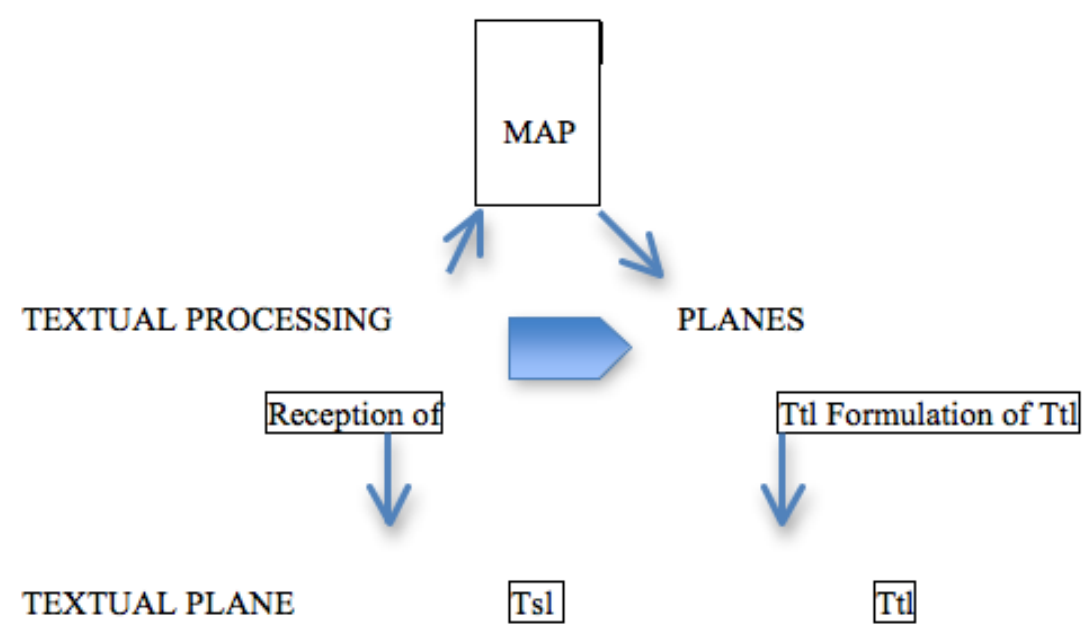

(Extracted from Holmes, 19:83)

Figure 2: Holmes' Two-plane text-rank Translation Model

In this model, Tsl refers to source-language text, while Ttl refers to target-language text. According to this model, translation takes place on two planes within the textual planes: a serial plane, where one translates sentence by sentence, and structural plane, on which one abstracts a 'mental conception' of the original text. Then, a translator will test each sentence during the formulation of the new, translated text.

The abovementioned theoretical theories and hypothesis suggest that translation activities can be studied and explored in greater details.

\section{Translation and Language Teaching}

Research indicates that translation has been used as one of the methods in language teaching, apart from the reading, audiolingual and audiovisual methods. Stern (2001), for instance, has exposed and compared these methods in terms of their features, sources, history, objectives, teaching method, theoretical assumptions and the assessment (pp. 452-476). He admitted that making such comparisons was not easy task, since "even the generic term 'method' is not unequivocal" (p. 452). Cook (2010), on the other hand, has argued on the importance of translation in language teaching and learning. Focusing solely on translation, he compares and assesses each translation method in language teaching from the 18th century until the present moment. His detailed argument and explanation on this issue has contributed to the area of language teaching, particularly to teachers who believe in using translation in their teaching. The availability of these separate writings by Stern (2001) and Cook (2010), no doubt, could enable language teachers to understand the development of language teaching and learning starting from the 18th century, apart from helping them to choose the most appropriate method or methods in their own teaching. Indeed, the evolution of various translation methods 


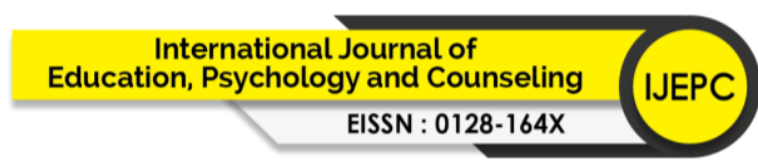

Volume 6 Issue 43 (November 2021) PP. 83-96

DOI 10.35631/IJEPC.643008

Special Issue: Issues and Challenges in English Education throughout the centuries has enabled researchers and educators to understand that translation could be practised differently.

\section{To Translate or Not To Translate}

Even though translation has long been regarded as one of the methods on EFL and ESL teaching, the issue has been debated throughout the years. At times, the failure of the GrammarTranslation method used in the 18th century and the ardent Reform Movement in the 19th century have influenced scholars and teachers to shun the method from their pedagogical sphere (Vermes, 2010; Cook, 2010; and House, 2013). It has been belittled in various terms, such as "unhelpful to learning, unusable, dull, authoritarian, unpopular, artificial, and slows students down" (Cook, 2010: 125). Translation, thus, has been outlawed and considered a disgrace in both ESL and EFL classrooms for many years.

However, research indicates that translation is not totally banned in teaching. House (2013), for instance, has presented the arguments against and for in pedagogical uses of translation. Among the objections are: translation into the foreign language interfered with the natural process of learning a foreign language and corrupted its use; translation from the foreign language was also rejected because it promotes passive knowledge about the foreign language; translation is misleading as it seduced learners into believing one-to-one correspondence of two languages; and translation per se was claimed an unnatural activity which could hinder the learning of four basic skills: listening, speaking, reading and writing (House, 2013:60-61). Evidently, both of these objections are based on his beliefs that language learning are confined to the four basic language skills, and translation is considered unnatural and detached from the actual language learning.

Still in a similar vein, Leonardi (2010) suggests a strong connection between translation and language teaching, whereby translators are considered good bilinguals and life-long language learners. According to Leonardi, the use of translation in language classes "is not a means aimed at training professional translators but rather a means to help learners acquire, develop and further strengthening their knowledge and competence in a foreign language" (p. 17). Hamzah Md. Omar (2014) also found out that translation is considered an essential teaching activity in rural schools. Suffice to note that translation is regarded as a useful pedagogic tool in the process of learning and teaching languages.

\section{Pedagogical Translation and Translation Pedagogy}

In order to understand the connection between teaching and the use of translation, perhaps the terms of Pedagogical Translation and Translation Pedagogy should be explained and differentiated. Both "Pedagogy" and "Translation" have their distinct meanings. Pedagogy is connected to the process of teaching and learning, whereas translation is defined in various ways, such as transference from the source language/text (SL/ST) into source language (TL/TT) (Cook, 2010; Leonardi, 2010, 2011; House, 2013) and rewriting or reproduction (Bassnett \& Lefevere, 1998; Toury, 2013). In addition, Vermes (2010) also makes distinctions between pedagogical translation and real translation. He differentiates between pedagogical translation and real translation in three ways: function, object and addressee (p. 84). In terms of function, pedagogical translation is an instrumental kind of translation in order to improve learner's foreign language proficiency. 


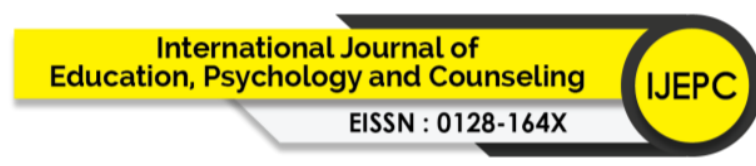

Volume 6 Issue 43 (November 2021) PP. 83-96 DOI 10.35631/IJEPC.643008

Special Issue: Issues and Challenges in English Education Numerous studies suggest that pedagogical translation supports and complements language proficiency in ESL and EFL classrooms (Leonardi, 2010; Vermes, 2010; Cook, 2010). Leonardi (2010), who considers pedagogical translation as the fifth skill in supporting and complementing language proficiency among bilingual learners, believes that translation activities could help learners to enhance analytical and problem solving skills which are relevant in their actual experiences. These two opinions reflect that pedagogical translation has a positive function in the second or foreign language learning.

Translation Pedagogy, on the other hand, deals with the knowledge about correct decoding of the source text (ST) and encoding into the target text. It is a tool or a set of guidelines for teachers to follow in using translation among bilingual students. The importance of this area in language teaching and learning is evident today. Baer \& Koby (2003), for instance, offer critical discussion of translation pedagogy with theoretical consideration, sample lessons and plans for teachers to refer as guidelines. According to them, the development of foreign language pedagogy over the last twenty-five years to bring the real world into the classrooms has shifted from the behaviouralist models (Skinner) to cognitive models (Bloom, Piaget, Vygotsky) of language acquisition. They suggested that teachers should refer to models of translation pedagogy, which are process-oriented and learner centered to translation.

In short, the findings from this study revealed pertinent areas to be focused on when using translation in ESL classroom, which include learners' proficiency levels, scaffolding, content of the materials, relevancy to the context and spiral learning. Indeed, the importance of this knowledge among teachers and education practitioners is also evident in another study conducted earlier by Kiraly, D. ((2000). This study stresses the importance of collaboration in both educating translators in their craft to avoid "hand me down" principle. He offers the strategies of objectivity and constructivity. He believes that teachers need to redefine their competency in translation by fusing the gap between their existing knowledge of translation and what is actually taking place in the classroom. Thus, the aspects of pedagogical translation and translation pedagogy work hand -in-hand in studying the use of translation in the ESL context.

\section{Translation Pedagogy}

In order to illustrate what translation pedagogy means, it seems worthy to exemplify two prominent translators in Malaysia. By doing so, the issues of translators' visibility and communication in local discourse can be understood.

\section{Za'ba as an Early Model}

The position of Zainal Abidin Ahmad, known as Za'ba, ought to be considered as a model translator in Malaysia due his role as a translator within the Malaysian historical and literary contexts. He had also written several books on Malay language such as Ilmu Bahasa Melayu I and Ilmu Bahasa Melayu II (1926 and 1927), Rahsia Ejaan Jawi (1929) and Ilmu Mengarang Melayu (1934). Za'ba had contributed his ideas and language expertise for the betterment of the nation. He has continued writing until the end of his life. Prior to his demise in 1973, he was conferred "Pendeta Bahasa" (trans. Sage of Language) in 1956, honoured as a visiting lecturer of Malay Language in the School of Oriental and African Studies, London (19471950), and worked as a lecturer in University Malaya. Two years after his retirement, the University of Malaya has conferred him the Honourary Doctorate of Letters. The Malaysian 


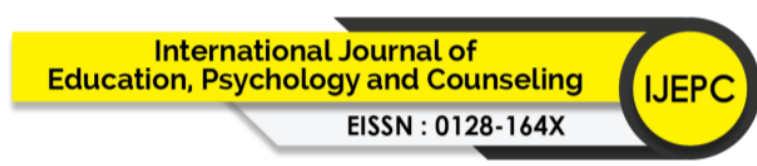

Volume 6 Issue 43 (November 2021) PP. 83-96

DOI 10.35631/IJEPC.643008

Special Issue: Issues and Challenges in English Education literary and educational histories have it that the contribution of Za'ba to the field of Malay studies and literature is enormous.

The first Malay translation of Shakespeare's work, Chérita-Chérita Duka Shakespeare (1929) was produced in a prose form based on Charles and Mary Lamb's Tales from Shakespeare(1807). This collection presents the first prose Malay translation of Shakespeare's tragedy plays comprising Hamlet, King Lear, Othello, and Macbeth. The tales were rewritten by Za'ba who, at that time was a chief Malay translator working under Dussek, the Director of the Translation Bureau, as part of the bureau's project to increase Malay reading materials among young children.

His exemplified translation pedagogy could be unfolded by analysing his craft in translating the tales. Among the strategies used, inter alia, are inserting L1 poetic discourse, replace culture-specific words and deleting phases considered inappropriate. Thus, his translated version seems domesticated to the target cultural context. His position as a trust-worthy translator seems crucial in exposing this western work to non-English literates in the early twentieth century.

\section{Muhammad Haji Salleh as a Modern Cross-cultural Model}

Another exemplified Malaysian writer and translator is the Malaysian National Laureate, Muhammad Haji Salleh. According to Md Salleh Yaapar (2005), he is not only a leading poet, but a respected scholar as well. As a professor of literature, he works endlessly in searching for Malay poetics in writing. He is a prolific writer who has produced tremendous amount of novels and poems apart from translating creative works and academic books from L2 to L1 or vice versa. He also translated non-English texts into L1. He represents a hybrid thinker similar to other Malaysian intellectuals who received higher education overseas. He has been exposed to William Shakespeare, Dylan Thomas, Joseph Conrad, naming just a few, for literary knowledge. He is also exposed to Susan Bassnett and Eugene Nida for translation theories (Muhammad, 2013). Both of these theories are descriptive. Among his published literary works include The Travel Journals of Si Tanggang II (1979), Beyond the Archipelago (1995) and Rowing Down Two Rivers (2000). He also translated the original version of Hikayat Hang Tuah into The Epic of Hang Tuah (2000).

Muhammad Haji Sallah is also an academician, literary critic and instrumental behind the formation of the Malaysian Institute of Translation and Books [Institut Terjemahan dan Buku Malaysia] as well as the Malaysian Translators' Association. Even though he perceived himself as a natural translator, he believes that one needs experience and training in order to become a good translator (Muhammad, 2013). He admitted that his 20 years of endeavor in trying to translate Hikayat Hang Tuah was challenging, due to the classic poetic of discourse used throughout the text. Indeed, this is the language used during $\mathrm{Za}$ 'ba's period. Thus, for Muhammad, before translating the text into L2, first he had to rewrite the sentences into the modern Malay. This process of rewriting is the approach suggested by Bassnett (2014) from the descriptive group. In addition, the concept of 'translator's 'mental conception' is evident in Holmes' model (1988). Thus, thus the descriptive frameworks seem evident in Muhammad's pedagogical translation. 


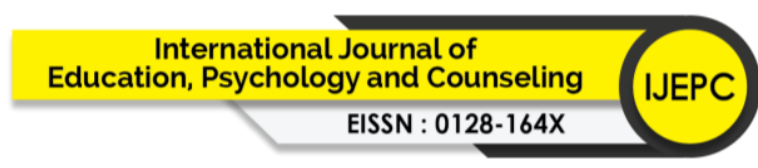

Volume 6 Issue 43 (November 2021) PP. 83-96

DOI 10.35631/IJEPC.643008

Special Issue: Issues and Challenges in English Education

To recapitulate, the practice of pedagogical translation employed by both Za'ba and Muhammad in translating the texts from L1 to L2 or vice versa, may be used as translation pedagogy. For Za'ba, he had adopted equivalence in translating the western tales into L1, following the local poetic of discourse. For Muhammad, on the other hand, he had to rewrite the original epic into modern L1 before translating it into L2. These two translation strategies are valuable in translation training.

\section{Pedagogical Translation}

\section{Leonardi's Translation Framework in Teaching}

To understand the connection between translation pedagogy and language learning, perhaps another framework ought to be illustrated. Leonardi (2010) has devised a translation pedagogy known as the Pedagogical Translation Framework (PTF), in assessing language proficiency within the Common European Framework of Reference for Languages (CEFR). The CEFR describes language proficiency in reading, writing, speaking and listening. Since translation is not included in this framework, she considers translation as the fifth skill in language proficiency.

Her framework is made up of three main types of translation activities: pre-translation, translation and post-translation activities. It has these elements:

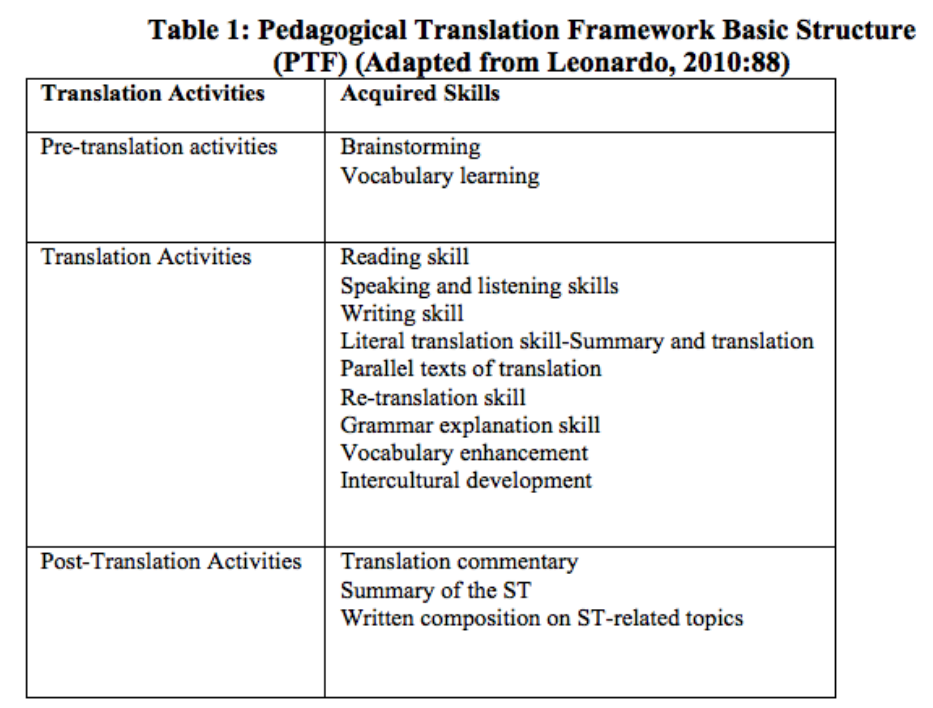

The PTF, according to her, could be employed at any level of proficiency and at any educational context. It allows language learning and translation training to take place at the same time. Thus, once her students have learned the skills involved, they will be able to execute pedagogical translation in their respective language classes.

\section{Discussion Of The Literature Review}

\section{Translation in English Language Classrooms}

The literature review has revealed that translation is considered as a normal practice in bilingual/multilingual classrooms. For instance, in their latest book on the area of Translation 


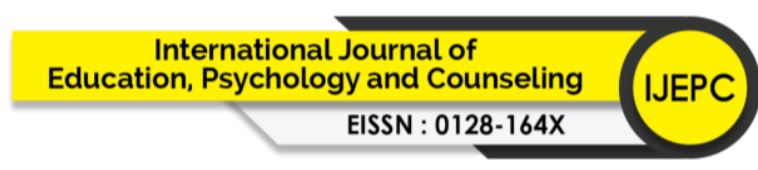

Volume 6 Issue 43 (November 2021) PP. 83-96 DOI 10.35631/IJEPC.643008

Special Issue: Issues and Challenges in English Education in Language Teaching (TILT), Laviosa \& Gonzalez-Davie (2020) have presented the issues of TILT from various perspectives, including theoretical issues, methods used by language teachers and educators in different levels of education and problems faced by translation trainers. The varieties of these perspectives have enabled teachers and translation trainers to understand what is going on in the process of using translation in bilingual/multilingual classrooms. Indeed, the theoretical side employed in this paper is the one suggested by Tory (2013) and his pioneers. Through this process-oriented theory, one is able to understand what is going on in the process of translation itself. This aspect is pertinent in teaching English to ESL students in Malaysia.

In the context of Malaysia, the teaching of English language to ESL students in both primary and secondary schools are subjected to the curriculums prescribed by the Malaysian Ministry of Education. For primary school teachers, they must follow the document known as Kurikulum Standard Sekolah Rendah (KSSR) (Standard Based English Language Curriculum for Primary School or SBELC). On the other hand, for those teaching secondary school students, they must follow the other document known as Kurikulum Standard Sekolah Menengah (KSSM) (Standard Based English Language Curriculum for Secondary School or SBELC). These curriculums are based on the modular concepts and they are aligned to CEFR levels (Ministry of Education, 2020). No allocation is given to the use of translation in these documents. In order words, teachers are not trained or guided to translate during language lessons. Ironically, they are teaching bilingual/multilingual students who are natural translators, and yet the students' natural learning potential has been denied. This is the practice gap that this study is trying to fill in. This reality goes in line with Cook (2010) and Leonardi (2010) suggestions. Both of them suggest that second or foreign language learning process should go in line with students' language readiness and first language (L1) inclination. Buy doing so, the process of teaching and learning will be natural and rewarding.

Next, let us look at the following propositions for this study.

\section{Proposition 1: Translation Is A Teaching Tool In A Multilingual Classroom}

\section{Pedagogical Translation}

Various studies in this area have shown that teachers translated in English language classrooms because they wanted to make sure that their students could understand the lesson taught (Cook, 2010, Noor Azaliya, 2019; Laviosa \& Gonzalez-Davies, 2020). Whether the lesson dealt with grammar or language arts, translation is proven to be a helpful teaching tool in ensuring that the process of teaching and learning could take place smoothly. Moreover, translation has not taken places all the time during the lessons. Pedagogical translation in the form of code switching also occurred during teacher-students interaction (Noor Azaliya et al., 2014). It should also be noted that it has not spoilt or replaced the English language lesson as intended in the lesson plan. Hamzah Md. Omar (2014) also regarded translation in ESL classrooms as indispensable tool. It has helped and enhanced the process of delivering the lesson plan following the students' linguistic ability, poetic and discourse of universe. By doing so, students' levels of confidence in learning the second language is enhanced and developed. 


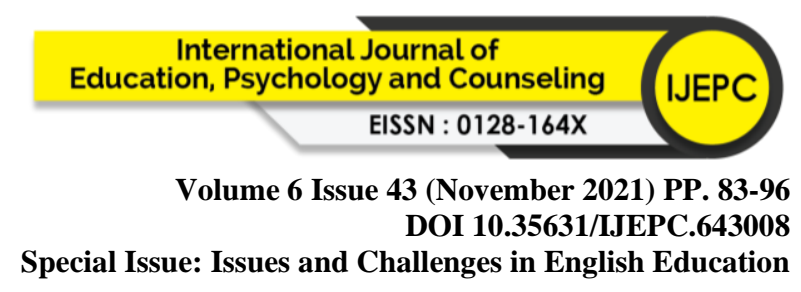

Proposition 2: Lack of Knowledge Among Teachers in Translation Skill

\section{Translation Pedagogy}

As mentioned by Muhammad (2013), one can be a natural translator, but learning pertinent skills of translation is better before one delves into this profession. What about ESL language teachers? In the Malaysian context, teachers and students are bi/ multilinguals. They use two or more languages. They are natural translators through code switching and code mixing (Gutierrez, 2018; Noor Azaliya, 2019). Perhaps, their experience in using more than one language has enabled them to communicate in both languages. However, there are other skills and translation theories that they must be aware of. As noted by Massey (2020), there should be a competency profile for every translator. Being bilingual is not enough. Other factors need to be learned as well in line with Toury's translational norms (2013). Thus, what they know and how they teach will make a difference.

\section{Proposition 3: Translation is A Process}

Translation is a process involving several factors. Thus, it requires a person to have an adequate knowledge on several factors, inter alia, grammatical components, context, cultural issues as well as his first language. Toury's framework of translational norms has enabled a person to analyse his/her role and purpose in doing translation. For a teacher, translation is employed as a tool for the sake of helping ESL students to understand the lesson of L2 (Cook, 2010, Leonardi, 2010). By knowing that translation itself is a process, a teacher can always restructure and rewrite his/her pedagogical translation based on the Descriptive theoretical frameworks shown earlier on.

The theory of rewriting propagated by Bassnett (2014) could enable a translator to keep on revising his/her translation so that it will suit the target culture. The example done by Muhammad Haji Salleh (2013) is worthy to emulate. Whether the process of translation is done in written or verbal form, one can always improve for a betterment of his/her delivery.

\section{Conceptual Model Development:}

\section{English Language Teaching (ELT) Translation Framework}

In this proposed framework, which is adapted from Leonardi's PTF (2010), a language teacher can conduct his/her pedagogical translation in a bilingual/multilingual setting within three stages: pre-teaching, while-teaching and post-teaching stages. This proposed framework is different from the former one. Leonardo's PTF only provides translation pedagogy in terms of suggested activities, while the adapted one provides both translation pedagogy and pedagogical translation. Teachers are able to use this framework for guidance in translation pedagogy. Upon completing his/her pedagogical translation, assessment can be made based on the five items in translational norms: language competency, translation purpose, material suitability, and equivalence of SL and TL and translation strategies. The comparison between Leonardi's PTF (2010) and the proposed ETF frameworks is illustrated below: 


\section{Table 2: A Comparison between PTF and ETF}

\begin{tabular}{|l|l|}
\hline Leonardi's PTF (2010) & The proposed ETF \\
\hline Pre-translation activities: & Pre-translation activities: \\
-Brainstorming & -Lesson plan preparation \\
-Vocabulary learning & -Students' proficiency identification \\
Translation activities: & Translation activities: \\
-Reading skill & Competency: \\
-Speaking and listening skills & Do teachers possess language competency in L1 and L2? \\
-Writing skill & Purpose: \\
-Literal translation skill & What is the purpose of using translation in teaching literature to \\
-Summary and translation & ESL students? \\
-Parallel texts of translation & Suitability: \\
-Re-translation skill & How do teachers assess the suitability of the selected text? \\
-Grammar explanation skill & -Equivalence: \\
-Vocabulary enhancement & What type of equivalence is evident in ESL translation pedagogy? \\
-Intercultural development & -Strategies \\
Post-Translation activities: & Which/Whose translation strategies are adopted? \\
-Translation commentary & Post-Translation activities: \\
-Summary of the ST & -Teaching reflection \\
-Written composition on ST- & -Reasons for using translation in teaching \\
related topics & -Assessing the selected translating strategy \\
\multicolumn{2}{|l}{} \\
\hline
\end{tabular}

The five items in the pedagogical translation column of the proposed ETF could enable translation educators to find out the answers to the following question:

What types of processes are involved when a teacher employs translation in teaching ESL students?

i. $\quad$ Does helshe have the language competency to do so?

ii. $\quad$ What types of decision-making processes are taking places?

iii. $\quad$ Why does he/she translate from L2 to L1 or vice versa?

iv. $\quad H o w$ does he/she reach equivalence from L2 to L1 or vice versa?

v. How does he/she translate from L2 to L1 or vice versa?

The answers to these sub-question questions, thus, could enable us to understand the processes involved in pedagogical translation.

\section{Conclusion}

The findings of this paper will direct language educators in three directions. Firstly, they will understand the processes involved in translation. Secondly, they will understand the key concepts involved in translation activities. Thirdly, they will understand their positions as English language teachers in bilingual/multilingual setting in a wide global community of TILT area. For translation trainers, they will learn the theories and issues involved in training their student-teachers. In doing so, it seems important for module designers to understand two basic concepts addressed throughout this paper. To simplify, the term translation pedagogy refers to the training aspect, while the term pedagogical translation refers to the execution of translation 


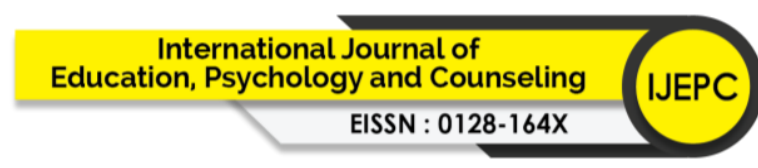

Volume 6 Issue 43 (November 2021) PP. 83-96 DOI 10.35631/IJEPC.643008

Special Issue: Issues and Challenges in English Education activities. To conclude, this paper has also illustrated a proposed translation framework, which could enable both concepts to merge in the process of language teaching and learning.

\section{References}

Baer, B. J., \& Koby, G. S. (2003). Beyond The Ivory Tower: Rethinking Translation Pedagogy. Amsterdam: John Benjamins Publishing Company

Bassnett, S. and Lefevere, A. (1998). Constructing Cultures. Clevedon: Multilingual Matters.

Bassnett, S. (2014). Translation Studies. Fourth edition. London: Routledge, Taylor and Frances.

Cook, G. (2010). Translation in Language Learning. Oxford: Oxford University Press.

Gutierrez, L. P. (2018). Translation in Language Teaching, Pedagogical Translation, and Code Switching; Restructuring the Boundaries. In The Language Learning Journal, (49), 219-239. doi.org/10.1080/09571736.2018.1534260

Hamzah Md. Omar \& Nik Zaitun Nik Mohamed (2014). TESL Undergraduate Student Teachers' View on Translation in a Rural School. In Journal of Teaching and Teacher Education, 2(1), 61-68. doi.org/10.12785/jtte/020105

Holmes, J. (1988). Translated! Paper on Literary Translation and Translation Studies. $2^{\text {nd }}$ edition. Amsterdam: Rodopi.

House, J. (2013). Translation. Oxford: Oxford University Press.

Howatt, A. P. R. (2000). A History of English Language Teaching. (Seventh impression). Oxford: Oxford University Press.

Kiraly, D. (2000). A Social Constructivist Approah to Translator Education. Empowerment from Theory to Practice. Machester:, UK: ST. Jerome.

Laviosa, S. \& Gonzalez-Davies, M. (2020). The Routledge Handbook of Translation and Education. London \& New York: Routledge

Leonardi,V. (2010). The Role of Pedagogical Translation in Second language Acquisition: from Theory to Practice: Bern, Switzerland: Peter Lang AG

Massey, G. (2020). Translation Teacher Training. In Laviosa, S. \& Gonzalez-Davies, M. (eds.). The Routledge Handbook of Translation and Education. London \& New York: Routledge, pp. 385-399.

Md. Salleh Yaapar. (2005). A Post-Colonial Poet with a Quest for Identity: Self and Other in the Works of Muhammad Haji Salleh. In Indonesia and the Malay World, (33), 293306.

Ministry of Education Malaysia (2020). Implementing The CEFR-Aligned Curriculum Second edition. Negeri Sembilan: English Language Teaching Centre, Ministry of Education.

Muhammad Haji Salleh. (2013). Untranslated Notes of an Untrained Translator. In Rokiah Awang, Aniswal Abd. Ghani \& Leelany Ayob. In The $14^{\text {th }}$ International Conference on Translation \& 7th Asian Translators' Forum. Science University of Malaysia: Malaysian Translators Association, 12-30.

Nik Zaitun Mohamed, Hamzah Md Omar \& Suhaida Omar. (2015). Bridging the Real World Englishes in the Rural ESL Classroom through Translation. In International Journal of Language Education and Culture Review, 1(2), 87-104. doi.org/10.21009/IJLECR.012.019

Noor Azaliya Binti Jumal, Asmaa AlSaqqaf \& Nik Zaitun Nik Mohamed. (2019). Code Switching in Malaysian Secondary ESL Classroom: A Preliminary Study from Sabah. In International Journal of Asian Social Science, Asian Economic and Social Society, 9(5), 327-334. 
Volume 6 Issue 43 (November 2021) PP. 83-96 DOI 10.35631/IJEPC.643008

Special Issue: Issues and Challenges in English Education

Stern, H. H. (2001). Fundamental Concepts of Language Teaching. (Eleventh impression). Oxford: Oxford University Press.

Toury, G. (2013). Pengajian Penterjemahan Deskriptif dan jangkauannya. Terj. Kuala Lumpur: ITBM.

Vermes, A. (2010). Translation in Foreign Language Teaching: A Brief Overview of Pros and cons. Eger Journal of English Studies (X), 83-93. 